\title{
Characterization of Different Parts of Oil Palm Fronds (Elaeis Guineensis) and Its Properties.
}

\author{
Noor Afeefah Nordin ${ }^{\# 1}$, Othman Sulaiman ${ }^{\# 2}$, Rokiah Hashim ${ }^{\# 3}$, and Mohamad Haafiz Mohamad Kassim ${ }^{\# 4}$ \\ ${ }^{\#}$ Division of Bio-resource, Paper and Coatings Technology, Universiti Sains Malaysia, 11800 Minden, Penang Island, Malaysia. \\ E-mail: ${ }^{1}$ epinordin@gmail.com; ${ }^{2}$ othman@usm.my; ${ }^{3}$ hrokiah@usm.my; ${ }^{4}$ mhaafiz@usm.my
}

\begin{abstract}
The study was conducted on characterizing the properties of oil palm fronds (Elaeis guineensis) from different parts. The fronds were cut to three parts which were the top, middle and bottom. The samples were chipped, dried in the oven of $50{ }^{\circ} \mathrm{C}$ and ground before they were characterized. The properties of the fronds were characterized using thermal gravimetric analyser (TGA), fourier transform infrared spectroscopy (FTIR) and x-ray diffraction (XRD). The results from TGA showed that the bottom part of the frond had the lowest percentage of residues which was $29.22 \%$ and the degradation temperature was $194.17{ }^{\circ} \mathrm{C}$. The FTIR spectra showed almost similar peaks for all samples. The bottom part of the frond had the highest crystallinity index which was 35.26 $\%$. The study proved that different parts of the frond had different characteristics due to its chemical compositions.
\end{abstract}

Keywords - oil palm fronds; thermal property; crystallinity.

\section{INTRODUCTION}

Wood is the major source of various products in the industry because of its strength and aesthetical properties. However, due to the concerns regarding future supplies and wood costs, many researchers have worked on the alternative ways to produce wood based products without depending on virgin wood source. Therefore, biomass wastes were chosen as a substitute to these materials. These biomass were modified and treated based on its suitability to be used for various products such as board making industry, bio-composites, natural preservatives, paper industry and etc.

One of the biomass that attracts wood-based industry's attention is oil palm (Elaeis guineensis). Oil palm originates from West Africa and was introduced to South East Asia in the last century [1]. It belongs to the species Elaeis guineensis under the family of Palmaceae. According to statistics, Malaysia has the largest oil palm plantation area which was reported to be 5.5 million hectares in 2013 and hence resulted being one of the biggest exporters of palm oil to the world [2]. This large plantation subsequently gives rise to a huge amount of biomass waste generated such as the oil palm trunks, fronds, empty fruit bunches and leaves left in the plantation area without being properly managed. Among all of the biomass, oil palm fronds are the major waste generated in the plantation area. The OPF are obtained during pruning to harvest fresh fruit bunch (FFB) which makes it available daily throughout the year. The abundance availability of oil palm in Malaysia makes it suitable to be used as an alternative raw material. To date, the OPF are currently under-utilized because they are being used for nutrient recycling and soil conservation in the plantation area [3]. Hence, pruned fronds are just left in the plantation without being properly managed.

Morphologically, the properties of the oil palm fronds would differ along the frond's stem and also at different age. A fundamental study on the properties of oil palm trunk was carried out differentiating the parenchyma and vascular bundles. It was found that the cell distributions and moisture content varied between the inner, middle and outer part of the trunks. This is attributed to the different ratios of parenchyma and vascular bundles in each part that was studied [4]. However, to date there is still no data available about the properties of oil palm fronds that varies between the top, middle and bottom part. Therefore, this study was carried out to determine the differences which makes it useful to be used for further reference before subsequent use of this material for the production of wood-based products.

\section{MATERIALS AND METHODS}

The OPFs were obtained from oil palm plantation in Nibong Tebal, Pulau Pinang, Malaysia. The leaves and bark were removed before they were cut to three parts which were the top, middle and bottom of the frond. These three parts were isolated from each other and were cut to small pieces prior to drying in the oven with a temperature of $50{ }^{\circ} \mathrm{C}$ for 
$24 \mathrm{~h}$ to avoid fungal attack. After drying, the fronds were ground to pass 400 mesh sieve easy way to comply with the conference paper formatting requirements is to use this document as a template and simply type your text into it.

\section{A. Sample preparation}

The OPFs were obtained from oil palm plantation in Nibong Tebal, Pulau Pinang, Malaysia. The leaves and bark were removed before they were cut to three parts which were the top, middle and bottom of the frond. These three parts were isolated from each other and were cut to small pieces prior to drying in the oven with a temperature of $50{ }^{\circ} \mathrm{C}$ for $24 \mathrm{~h}$ to avoid fungal attack. After drying, the fronds were ground to pass 400 mesh sieve.

\section{B. Thermo gravimetric analysis (TGA)}

Thermogravimetric analysis was performed to determine the thermal properties of the oil palm fronds fibers for top, middle and bottom part. The thermal stability data were collected on a Perkisn Elmer TGA 7 thermogravimetric analyzer under linear temperature conditions. The temperature was swept from $50{ }^{\circ} \mathrm{C}$ to $800{ }^{\circ} \mathrm{C}$ for samples of $10-15 \mathrm{mg}$ placed in an aluminium pan at a heating rate of $10{ }^{\circ} \mathrm{C} / \mathrm{min}$ under nitrogen atmosphere.

\section{Fourier transform infra-red spectrometry (FTIR)}

The presence of any changes in functional groups of the samples during the treatment was measured by FT-IR Spectroscopy. The pellets were prepared by mixing approximately $5 \mathrm{mg}$ of particles samples with $95 \mathrm{mg}$ of finely ground $\mathrm{KBr}$ before pressing it into a transparent pellet. Spectra were viewed using a Nicolet infrared spectrophotometer (Avatar 360 FT-IR E.S.P) machine. The spectra produced are transmittance mode between wave numbers of $4000 \mathrm{~cm}^{-1}$ and $500 \mathrm{~cm}^{-1}$.

\section{X-ray diffraction analysis $(X R D)$}

The X-ray diffraction analysis was performed to check the crystallinity index of the oil palm frond fiber. Structural and phase analyses of the samples were measured by using an Xray diffractometer with $\mathrm{CuK} \alpha$ radiation (wavelength of $1.5406 \AA$ ) generated at an operating voltage and current of $40 \mathrm{kV}$ and $30 \mathrm{~mA}$, respectively. The $\mathrm{CuK} \alpha$ radiation was filtered electronically with a Ni-filter. A $2 \theta$ angle range from $5^{\circ}$ to $50^{\circ}$ in reflection mode was scanned at $2 \%$ min. The crystallinity index was calculated based on the following equation:

$$
\operatorname{CrI}(\%)=\left(\mathrm{I}_{200}-\mathrm{I}_{\mathrm{am}}\right) / \mathrm{I}_{200} \times 100
$$

Where $I_{200}$ is the peak intensity corresponding to crystalline and $\mathrm{I}_{\mathrm{am}}$ is the peak intensity of the amorphous fraction [5].

\section{RESULTS AND DISCUSSION}

Thermal degradation and percentage of weight loss of the samples were determined by TGA analysis. It can be observed from Fig. 1 that the trend of degradation were similar between all of the samples. However, the bottom part had the highest degradation temperature which was 194.17 ${ }^{\circ} \mathrm{C}$ followed by middle and top part which were
191.03 and $187.42{ }^{\circ} \mathrm{C}$ respectively. Meanwhile the weight loss or residue were almost similar which were 29.22, 29.30 and $29.44 \%$ for the top, middle and bottom part respectively.

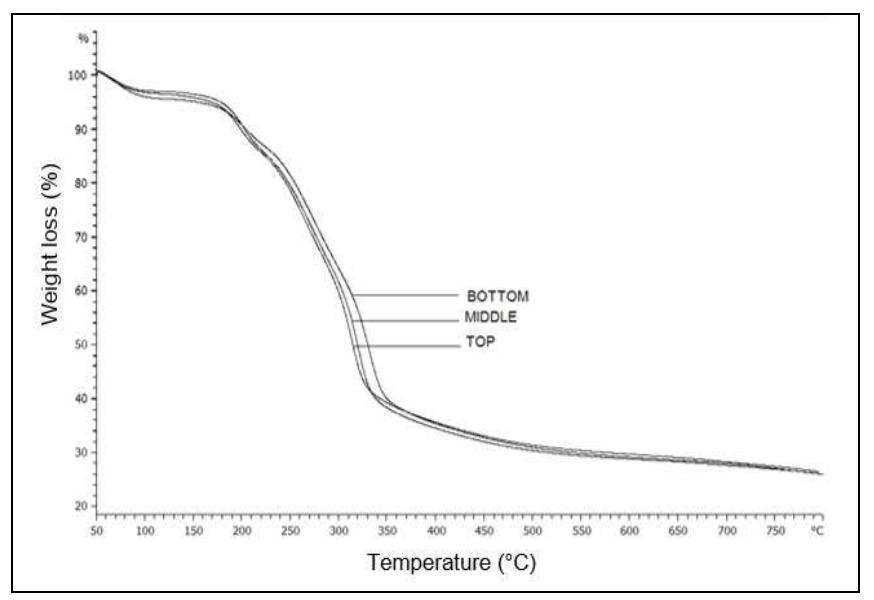

Fig. 1 Thermal degradation analysis of top, middle and bottom part of oil palm frond

The initial weight loss from 50 to $150{ }^{\circ} \mathrm{C}$ was attributed to the evaporation of water in cellulose fiber while the temperature ranges between 150 and $250{ }^{\circ} \mathrm{C}$ showed depolymerization of non-celluloses such as hemicelluloses and lignin. Apart from that, it also corresponded to the breakage of the glycosidic bonds. The temperature between 300 and $350{ }^{\circ} \mathrm{C}$ indicated the degradation of the $\alpha$-celluloses available in the samples [6]. The difference in degradation temperature showed that the bottom part was more resistant to thermal compared to the middle and top part. This can be ascribed to the higher amount of crystalline structures of the sample as supported by the XRD analysis. It was reported that a greater crystalline region requires a higher degradation temperature [7].

The FTIR spectroscopy determines types of functional group available in the sample. Fig. 2 showed the FTIR spectra of all three samples and it can be observed that the spectra has almost similar trend for all of the samples. This is mainly because all of them were obtained from the same source and were not subjected to any treatments or modifications hence resulted in having the same chemical compositions.

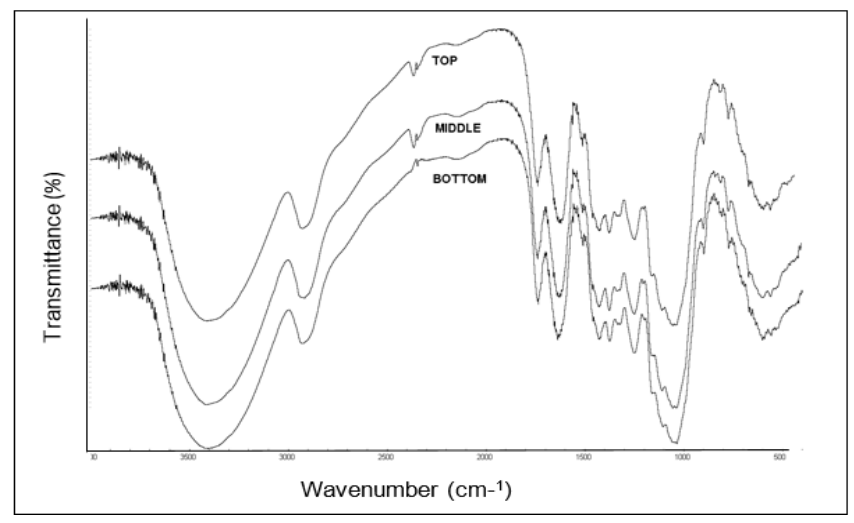

Fig. 2. FTIR spectroscopy of the top, middle and bottom part of oil palm frond 
The peaks in the 3,344-3,415 and 1,635-1,645 $\mathrm{cm}^{-1}$ region corresponded to $\mathrm{O}-\mathrm{H}$ stretching and bending vibrations, respectively, of hydrogen bonded hydroxyl $(\mathrm{OH})$ groups of cellulose and absorbed water [8]. The peaks at $1,701-1,737 \mathrm{~cm}^{-1}$ were attributed to the $\mathrm{C}=\mathrm{O}$ stretching of hemicellulose and lignin while the $\mathrm{C}=\mathrm{C}$ aromatic skeletal vibration of lignin were indicated by the peaks at 1,509$1,609 \mathrm{~cm}^{-1}$. The peaks at 1,058-1,060 and $896-900 \mathrm{~cm}^{-1}$ were attributed to the $\mathrm{C}-\mathrm{O}$ stretching and $\mathrm{C}-\mathrm{H}$ rocking vibrations of cellulose [9].

Crystallinity index of the samples was performed using the x-ray diffraction analyzer. Generally, lignocellulosics materials consist of crystalline and amorphous region and a greater crystallinity index corresponds to the higher crystalline region compared to amorphous region in the structure.

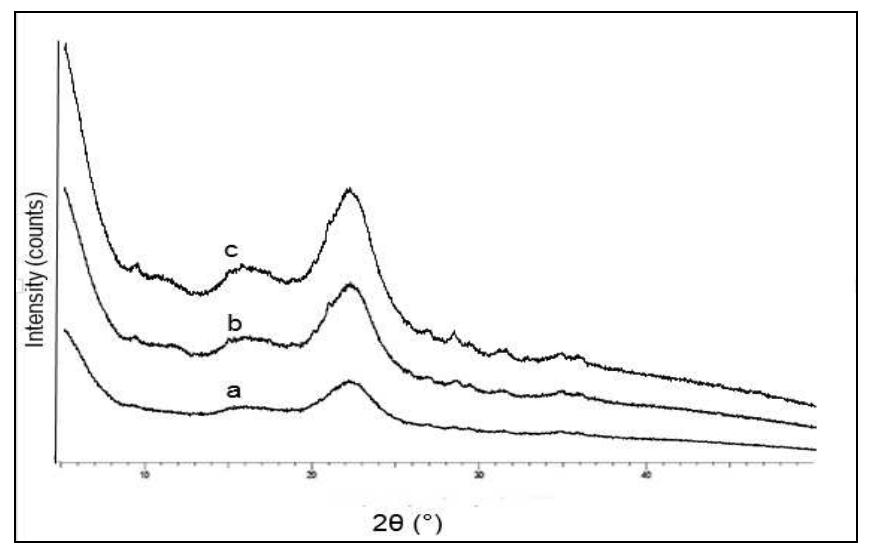

Fig. 3 X-Ray diffraction of a) top, b) middle and c) bottom part of oil palm frond.

Based on the intensity from Fig. 3, the bottom part had the highest crystallinity index which was $35.26 \%$ while middle and top part was 34.22 and $33.71 \%$ respectively. This shows that the bottom part had greater amount of cellulose and lesser amount of hemicellulose and lignin compared to the other two samples. The diffractogram was presumed to represent typical cellulose I because it showed a peak at $2 \theta=$ $22^{\circ}$ and a shoulder in the region $2 \theta=19^{\circ}$ [10]. In conjunction with the result, it can be concluded that the bottom part has a greater content of vascular bundles compared to parenchyma. This is because vascular bundle has higher amount of cellulose and contributed to the increase in crystalline region of the sample. On the other hand, the ratio of vascular bundles to parenchyma decreased from middle to the top part resulting in a lower crystallinity index.

\section{CONCLUSIONS}

This study showed that there were some differences between the different parts of oil palm frond. Based on the results from TGA and XRD, it can be concluded that the bottom part of the OPF has the best properties compared to the middle and top part. However, the differences in values were not in a big range. This finding can be used as a reference for a further research utilizing the oil palm frond as raw materials.

\section{ACKNOWLEDGMENT}

The authors would like to acknowledge Ministry of Higher Education (MOHE) for the MyPhd scholarship to Noor Afeefah Nordin, Universiti Sains Malaysia for Research University Grant 1001/PTEKIND/811255 and Institute of Postgraduate Studies for conference funding.

\section{REFERENCES}

[1] S. Sumathi, S. Chai and A. Mohamed. "Utilization of oil palm as a source of renewable energy in Malaysia". Renewable and Sustainable Energy Reviews, vol. 12, pp. 2404-2401, 2008.

[2] (2014) Malaysian Palm Oil Council website. [Online]. Available: http:// www.mpoc.org.my

[3] M.K.M. Ahamad, R. Mohd, H. Ariffin, M. Noriznan, J. Salihon, Y. Shirai and M. Ali. "Renewable sugars from oil palm frond juice as an alternative novel fermentation feedstock for value added products" Bioresource technology, vol. 110 pp. 566-571, 2012.

[4] S.F Mhd Ramle, O. Sulaiman, R. Hashim, T. Arai, A. Kosugi, H. Abe, Y. Murata, and Y. Mori, "Characterization of parenchyma and vascular bundle of oil palm trunk as function of storage time" Lignocellulose, vol. 1(1) pp. 33-44, 2012.

[5] L. Segal, J.J Creely, A.E. Martin, and C.M. Conrad. "An empirical method for estimating the degree of crystallinity of native celluloses using diffractometer" Textile Research, vol. 29, pp. 786-794, 1959.

[6] A. Sonia, and K.P. Dasan. "Chemical, morphology and thermal evaluation of cellulose microfibers obtained from Hibiscus sabdariffa" Journal of Carbohydrate Polymers, vol. 92(1), pp. 668674, 2013.

[7] S. Ouajai, and R.A. Shanks. "Morphology and structure of bioscouring hemp fibre" Journal of Macromolecular Bioscience, vol. 5, 124-134, 2005.

[8] F. Fahma, S. Iwamoto, N. Hori, T. Iwata, and A. Takemura. "Isolation, preparation, and characterization of nanofibers from oil palm empty fruit bunch (OPEFB)". Journal of Cellulose, vol. 17, 977-985, 2010.

[9] M.F. Rosa, E.S. Medeiros, J.A. Malmonge, K.S. Gregorski, D.F. Wood, L.H.C. Mattoso, G. Glenn, W.J. Orts, and S.H. Imam. "Cellulose nanowhiskers from coconut husk fibers: effect of preparation conditions on their thermal and morphological behavior" Journal of Carbohydrate Polymer, vol. 81(1), pp. 83-92, 2010.

[10] S. Elanthikkal, U. Gopalakrishnapanicker, S. Varghese, and J.T. Guthrie. "Cellulose microfibres produced from banana plant wastes: Isolation and characterization" Journal of Carbohydrate Polymers, vol. $80,852-859,2010$. 